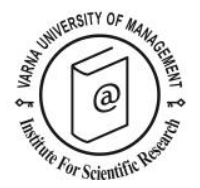

\title{
The Wrong Way:
}

\section{An alternative critique of the Camino de Santiago}

\author{
Jeffrey Overall ${ }^{1 *}$
}

Received: 25/01/2018 Accepted: 24/10/2018

\footnotetext{
${ }^{1}$ Associate professor of entrepreneurship and strategy in the Faculty of Business and Information Technology at the Ontario Tech University, 2000 Simcoe St N, Oshawa, ON L1G 0C5. 905.721.8668 ext. 2612. Email: jeffrey.overall@uoit.ca

* Corresponding author

Coordinating editor: Stanislav Ivanov
}

\begin{abstract}
Dating back to the $11^{\text {th }}$ century, the Camino de Santiago, a spiritual journey to the site of the final resting place of the apostle Saint James, has been important to pilgrims for centuries. With the aim of escaping the monotony of daily life, the reasons for embarking on the pilgrimage have changed little. Although obvious societal changes have occurred since the $11^{\text {th }}$ century, many modern pilgrims attempt to travel similarly as those from ancient times. However, pilgrims that do not conform to perceived 'authentic' behaviors are often derided and left feeling alienated. Through ethnography, I attempt to explore the themes of: authenticity, social pressure, and pilgrimage as a tourist product within the context of the Camino de Santiago. By uncovering the challenges of the modern pilgrim, the main contribution to knowledge of this research involves detecting how escapism may not address the root of one's dissatisfaction.
\end{abstract}

Keywords: Authenticity; Camino de Santiago; escapism; pilgrim; pilgrimage; pilgrimage as a tourist product; social pressure;

Citation: Overall, J. (2019) The Wrong Way: An alternative critique of the Camino de Santiago. European Journal of Tourism Research 22, pp. 62-78

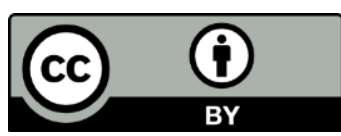

62
This work is licensed under the Creative Commons Attribution 4.0 International (CC BY 4.0). To view a copy of this license, visit https://creativecommons.org/licenses/by/4.0/ 


\section{Introduction}

Dating back to the $11^{\text {th }}$ century, the Camino de Santiago, a pilgrimage to the site of the final resting place of the apostle Saint James, in Santiago de Compostela, has been important to travelers for centuries. Many pilgrim routes to Santiago exist, but the most popular, the Camino Frances, follows 800 kilometers from Saint-Jean-Pied-de-Port in southern France to Santiago de Compostela in Spain. This route passes through the dense forests of Pamplona in Navarre, the famous wine region of La Rioja, and the historic villages of Burgos, Leon, and Galicia (Murray, 2014; Slavin, 2003). Although the pilgrimage peaked in the $15^{\text {th }}$ and $16^{\text {th }}$ centuries, after a sharp decline, there has been a resurgence over the past decades (Graham \& Murray, 1997) Traditionally, pilgrims undertook pilgrimages, namely “... a journey resulting from religious causes, externally to a holy site, and internally for spiritual purposes and internal understanding (Antunes and Amaro, 2016, p. 511)."

In contemporary times, many modern pilgrims remain drawn to the traditional (or authentic) pilgrim experience (Mendel, 2010). Pilgrims, in their desire to have an authentic experience, attempt to travel the Camino de Santiago as similar to the traditional medieval pilgrims and, for the length of their journey, attempt to avoid modern conveniences, such as: public transportation, luxury hotels, and baggage transportation services. As a result, the Camino de Santiago has been, and continues to be, a harsh undertaking involving walking for several hours per day, carrying a large pack, and sleeping in less-than-desirable locations. As a result of the pain and suffering that ensues from these conditions, pilgrims form bonds of support and assist one another through a very welcoming and inclusive process. Very much aligned to the Catholic teachings surrounding forgiveness, pain and suffering form the basis of the Camino (Egan, 2010), which is considered important to the penance that stimulates spiritual growth (Murray, 2014).

This perceived masochistic undertaking provides pilgrims with a temporary withdraw, or escape, from modern living to stimulate selfreflection and internal growth. Contemporary pilgrims, whom have reached a point of stagnation, which often include bouts of depression in their lives, are attracted to the spiritual and personal development that tend to emerge from participating in an authentic pilgrim experience (Egan, 2010). Although a form of escapism, individuals remain connected to life beyond the Camino through information technology devices (Antunes and Amaro, 2016), which enables them to escape, temporarily, the pain and suffering of the Camino. Similarly, the Camino provides many people, through the social norms of consuming at least a bottle of wine, daily, further escapism opportunities (Egan, 2010). To this end, there appears to be several layers of escapism that occur along the Camino, which might not necessarily help the individual in addressing the root of their dissatisfaction (Overall, 2017).

Although religion remains important, contemporary pilgrims are motivated by other, more secular (Nilsson, 2013; Warkentin, 2018), factors, namely: cultural, spiritual, health (Antunes and Amaro, 2016), a vacation, or to have fun. As emphasized through the growing exposure in popular culture, such as literature, documentaries, and the 2010 Hollywood production The Way, (Murray, 2014), the Camino de Santiago has emerged as an important tourist destination in the $21^{\text {st }}$ century (Collins-Kreiner and Wall, 2015; Smith, 2018). Regardless of the popularity and the seemingly positive economic advantages that this influx in tourists bring to the villages along the way, traditionalists, such as the Catholic authorities have expressed their concerns (Oviedo et al., 2013). To this end, authorities are refusing to grant 'certificates of completion' to those that do not embark on the journey for religious or cultural purposes. As a function of this, pilgrims, themselves, are displaying disdain toward pilgrims that do not appear to be behaving 'authentically'. Pilgrims tend to put significant social pressure on one another to display traditional pilgrim behaviors, such as carrying their own packs, avoiding public transportation, and sleeping in hostels (Graham \& Murray, 1997). To avoid the negative perceptions among other travelers, many pilgrims attempt to conceal their unauthentic behaviors (Collins-Kreiner and Wall, 2015), which ultimately has an impact on the overall pilgrim experience (Digance, 2006). Although, 
traditionally, a welcoming and inclusive process, the tension between tourists on the Camino pertaining to authenticity has led to the pilgrimage to be considered alienating and stressful to some (Graham and Murray, 1997; Slavin, 2003).

In this research, I embarked on an ethnographic study of the Camino de Santiago. The aim of this study to understand: (1) how the critiques of other pilgrims affect one's experiences and (2) how escapism affects the journey. These questions led to the emergence of three important themes: authenticity, social pressure, and pilgrimage as a tourist product. By critiquing the Camino de Santiago within the context of authenticity, the main contribution to knowledge of this research involves detecting how escapism may not address the root of one's dissatisfaction. In the first section, a brief background of the Camino de Santiago is presented. The methods used to conduct the research are outlined. In the subsequent sections, the results are discussed.

\section{Camino de Santiago - Background}

During the peak of the Camino in the $12^{\text {th }}$ century (Mendel, 2010), it is believed that there were as many as 500,000 pilgrims every year (Murray, 2014). Although interest in the Camino waned in the $16^{\text {th }}$ century, a surge in pilgrims occurred in the $19^{\text {th }}$ and $20^{\text {th }}$ centuries, partially as a result of UNESCO declaring Santiago de Compostela as a World Heritage site in 1985 (Antunes and Amaro, 2016). Although a far cry from the number of pilgrims during the medieval period, there has been a significant growth of pilgrims from nearly 3,000 in 1987, 125,000 in 2008, and up to 240,000 pilgrims in 2014 (Antunes and Amaro, 2016; Mendel, 2010).

As a result of the heightened interest, partially fueled by popular culture, there has been a surge in businesses that offer low-cost and efficient networks of hostels, restaurants, and shops to cater to the needs of pilgrims making the Camino a popular tourist product (Oviedo et al., 2013). For pilgrims that do not want to carry their luggage, there are low-cost logistics services that allow pilgrims to ship their bag from location-to-location. There are also higherend private accommodations available to pilgrims that do not wish to sleep in budget refuges.

Traditionally, pilgrims: fasted, travelled for several hours per day, did not stay in the same location for more than one night, refrained from grooming, slept in uncomfortable accommodations, did not spend money, actively sought suffering, and walked alone (Graham and Murray, 1997). The rules of the Camino are simple: follow the yellow markers west by travelling a short distance, daily, until you reach Santiago (Egan, 2010). Currently, the main form of pilgrim transportation involves walking with nearly $90 \%$ of the people completing the Camino on foot (Antunes and Amaro, 2016). However, given the hectic structure of modern living and the difficulty in securing one month away from one's responsibilities, cycling is becoming an increasingly popular mode of travel with $10 \%$ of pilgrims completing the Camino this way (Antunes and Amaro, 2016). Many pilgrims also drive.

However, some pilgrims believe that the Camino is not for cars (Murray and Graham, 1997). Others suggest that the pilgrims whom do not travel by the traditional modes of walking, do not carry their own bag (Mendel, 2010), book accommodations in advance, and avoid staying in less-than-desirable accommodations, are perceived as an 'unauthentic'. Although there is no agreed upon definition of an authentic pilgrim (Graham and Murray, 1997), people suggest that the: spiritual, internal enlightenment, self-discovery, and personal growth (Collins-Kreiner and Wall, 2015) can only be realized by those that follow the authentic approaches to the Camino (Mendel, 2010). In other words, individuals that do not embrace tradition, are not considered to be 'authentic' pilgrims (Slavin, 2003). As a result, these unauthentic pilgrims can be treated cynically, excluded, and often bullied. Due to these differing views, there have been instances of tensions and social pressures between locals, visitors, and pilgrims (CollinsKreiner and Wall, 2015) within the context of authenticity. This tension around authenticity and the resulting social pressure can have a negative impact on the experience. 


\section{Authenticity}

Although it has been suggested that authenticity is a difficult term to define (Graham and Murray, 1997), Xiarhos (2016) contends that authenticity is about one's identity, purpose, and intent. He further argues that the authentic pilgrim “... becomes consumed by the devotional-spiritual act of pilgrimage itself whereby the pilgrim is no longer defined by the secular identity being left behind (Xiarhos, 2016, p. 2)." Authenticity involves holding true to one's self and acting genuinely. Others (e.g., Belhassen et al., 2008) suggest that authenticity involves being authentic to oneself and behaving in ways that one normally would. Cohen (1988) suggests that modern living is inauthentic and pilgrims seek to experience authenticity through spiritual journeys like the Camino de Santiago. This quest for a deeper, authentic experience is a significant factor in the decision to embark on this journey (Carbone et al., 2016). Pilgrims perceive that the overall experience, inclusive of adversities, is vital to an authentic pilgrimage.

Kelner (2001) suggests that even those that attempt to behave in an authentic way, there are always instances of unauthenticity. "No matter where one tours, one need not look hard to find breaches in the fence separating the supposedly authentic from the supposedly inauthentic. And if one insists, the concept will collapse entirely under its own weight (Kelner, 2001 , p. 9)." Due to the fixation on authenticity, it has been suggested that pilgrims experience inauthenticity as a result of spending too much of one's energy on attempting to 'do it right' (Xiarhos, 2016). In this way, they attempt to avoid many of the modern conveniences, such as technology, that are an important aspect, and also authentic, to contemporary society (Xiarhos, 2016). Although pilgrims seek to behave authentically, they, ironically, behave in unauthentic ways.

As outlined, authentic pilgrim behaviors typically involve: carrying one's backpack, walking for several hours per day, and, when arriving at a suitable destination, seeking a refuge without making a reservation in advance with the hopes that an omnipotent being, such as: God, karma, fate, or the universe, will provide one with a bed. The bed, usually a bunkbed that can be uncomfortable, is located in a large room with anywhere from six to 30 people. Slavin (2003) found that this sleeping environment was full of snoring and smelly bodies.

\section{Social pressures}

In the extant literature, it is suggested that pilgrims experience various forms of social pressures (Caidi et al., 2018). These include pressures from their responsibilities back home, pressures surrounding the tension between consumerism and spirituality (Caidi et al., 2018), and pressures from other pilgrims on how one should behave. Due to the perceived need to access WIFI, continuously, Caidi et al (2018) suggests that the pressures involving consumerism, social media, and pressures from other pilgrims are often linked. As a result of the stress associated with the need to remain constantly connected, many travel services providers encourage pilgrims to detach from technology. This has proven challenging and many do not heed these suggestions (Caidi et al., 2018). Many pilgrims continue to post images on social media, as a form of self-promotion to attract followers and to gain exposure, throughout their journeys and become heavily focused on technology. Several pilgrims consider remaining connected to social media as a vital part of their pilgrimage (Caidi et al., 2018). However, this behavior has led to much tension among pilgrims as some attempt to avoid technology as much as possible (Caidi et al., 2018). This pressure leads to pilgrims criticizing others by suggesting that they are defiling the pilgrimage tradition (Caidi et al., 2018). Perpetual thoughts from home and the need to stay connected has been argued to be fatal to the pilgrim experience as these constant distractions lead many to feel as though they have never left home (Xiarhos, 2016).

\section{Pilgrimage as a tourist product}

As others have suggested (e.g., Higgins and Hamilton, 2011; Plichta, 2016), the Camino, itself, is a marketplace whereby various providers, such as: hotels, restaurants, boutiques, and tour operators vie for the pilgrim dollar. Santos (2002) argues that this focus on consumption has affected the pilgrim identity. Now, pilgrimages are becoming an attractive 
market in the travel and tourist industry. The focus by travel agencies on creating authentic pilgrimage experiences, the line between a pilgrim and a tourist has become increasingly blurred. To this end, it has been suggested that there is little to no difference between a tourist and a pilgrim (Dominguez and Alonso, 2019). Higgins and Hamilton (2011, p. 262) explain the similarities between the modern pilgrim and a tourist in the following narrative:

"The pilgrim is increasingly viewed as a tourist and the pilgrimage site becomes the marketplace where hotels, souvenir shops, restaurants and tour operators all compete to attract the lucrative pilgrim consumer. In this respect, pilgrimage sites provide an overlapping of the sacred and the profane, offering an appropriate context to explore and seek understanding of the complex relationship between religion and consumerism."

Cohen (1988, p. 373) further describes the modern pilgrimage context as follows:

"Since modern society is inauthentic, those modern seekers who desire to overcome the opposition between their authenticity-seeking self and society have to look elsewhere for authentic life. The quest for authenticity thus becomes a prominent motif of modern tourism, as MacCannell (1973, 1976) so incisively showed"

Indeed, it is argued that the majority of those that walk the Camino are in fact tourists who are curious about Santiago and the route toward it, not pilgrims.

\section{Method}

Researchers have used various methods to study pilgrims along the Camino de Santiago, including both quantitative and qualitative methods (e.g., Slavin, 2003). Both methods contain their advantages and disadvantages. In this study, the aims were primarily exploratory and with the desire to develop a deeper understanding of the chosen phenomena, such as: authenticity, social pressures, and pilgrimage as a tourist product within the context of the Camino de Santiago. Although quantitative methods, such as structural equation modelling, can be used for exploratory purposes (Overall, 2013), there are challenges with probing participants in an organic follow-up nature. Even though qualitative methods offer researchers the opportunity to probe and observe the behaviours of participants, the results and findings are not generalizable (Robson, 2002), which is the main limitation of qualitative methods. Other qualitative methods were considered for this research, such as indepth interviews; however, this method does not provide the researcher with the ability to observe the behaviours of the pilgrim after the interviews are completed. To this end, ethnography not only allows researchers to interview participants, but it also allows them to observe their behaviour.

Consistent with Carbone et al. (2016) and Slavin (2003) who walked the Camino, an ethnographic approach is used in this research. Specifically, Carbone et al. (2016) chose to experience the pilgrim lifestyle by becoming pilgrims, travelling with them, and fully immersing themselves in the pilgrim experience along the road to Santiago. Slavin (2003) suggests that, through the interactions with other pilgrims, walking the Camino offers a good research approach. Following the extant literature, I travelled along the Camino de Santiago as a pilgrim, lived the pilgrim experience, and fully immersed myself with the studied phenomenon (Carbone et al., 2016) through ethnography. As outlined by Robson (2002), ethnography is an exploratory qualitative approach that involves three main phases of: description, analysis of themes, and interpretation. This process involves various iterations between observation, reflection, analysis, and interpretation. Through ethnography, I was able to develop an enhanced perspective of not only the Camino, in general, but also those that travel along it (Bryman \& Teevan, 2005). The interpretations gained through this provided a rich perspective of the cultural experiences of a modern pilgrim (Robson, 2002; Silverman, 2008).

The primary data sources for this research involve my: observations, interpretations, and reflections upon the conversations, interactions, narratives, and perceptions that $I$ experienced along the Camino de Santiago. This primary data was captured in daily reflections through a personal journal. My 
pilgrimage was along the Camino Frances that began in the first week of May 2016 in SaintJean-Pied-de-Port, France and ended 28-days later in Santiago de Compostela, Spain. I originally became aware of the Camino over a decade (through a novel by Paulo Coehlo entitled The Pilgrimage) prior to my journey and, more recently, I came across information about the pilgrimage through the extant literature and popular culture, which further sparked my fascination with this perceived fun vacation.

\section{Data Analysis}

To analyze the data, I followed a general interpretivist approach that consisted of using grounded theory techniques. Similar to grounded theory, I relied on coding procedures to segregate the data into themes. Different from grounded theory, I only analyzed the data after the ethnography was complete and did not rely on the constant comparison approach of collecting data, analyzing it, coding it, and collecting data anew (Suddaby, 2006). Put differently, there was a clear separation from data collection and analysis (Overall \& Wise, 2016).
To facilitate the analysis, I transferred the contents of my journal into a word processing document using the Dragon speech-recognition software. Once in the word processing software, I used the color-coded comments feature in the Microsoft Word program (Ojastu et al., 2011; Overall \& Wise, 2016) to create codes and categories. By following this approach, I uncovered several important themes. In Table 1, I outline a descriptive analysis of these codes to demonstrate the frequency that they appeared in my data. By following this word repetition approach (D'Andrade, 1995), I was able to assess the most important themes and, in turn, place them into categories (Overall \& Wise, 2016).

The important themes that emerged appeared to be surrounding critiquing pilgrims and the pilgrimage, in general, within the context of authenticity. Pain and suffering emerged as an important theme surrounding the pilgrimage (experience) as a tourist product. There were also positive pilgrim experiences that arose through self-reflection. Alcohol consumption and technology were interesting social pressure themes. Next, the process of axial

\section{Table 1. Open-coding Examples}

\begin{tabular}{lc}
\hline Theme & $\begin{array}{c}\text { Number of } \\
\text { occurrence }\end{array}$ \\
\hline Critiquing pilgrims & 12 \\
Technology & 7 \\
Unconventional or rule-breaking behaviour & 7 \\
Self-reflection & 6 \\
Complaining and not enjoying myself & 5 \\
Pilgrim experience & 4 \\
Critiquing religion & 4 \\
Positive outlook & 3 \\
Pain and suffering & 3 \\
Alcohol consumption & 3 \\
Cynical & 2 \\
Critiquing pilgrimage & 2 \\
Pilgrim hypocrisy & 2 \\
Ethically questionable behaviour & 1 \\
Pilgrim tradition & 1 \\
\hline
\end{tabular}

Table 2. Axial Codes

\begin{tabular}{ll}
\hline \multicolumn{1}{c}{ Category } & \multicolumn{1}{c}{ Themes } \\
\hline Authenticity & (1) critiquing pilgrimage and critiquing pilgrims \\
Social Pressures & (1) technology and (2) alcohol consumption \\
Pilgrimage as a tourist product & (1) pain and suffering \\
\hline
\end{tabular}


coding, which involves returning to the original transcripts and themes for an additional review (Silverman, 2008), began. Through this process, several themes that seemed less important, such as ethically questionable behaviour were removed whilst other themes were combined into categories (Strauss \& Corbin, 1990).

From this process, selfishness was combined with pilgrimage as a tourist product. Considering that the pilgrim hypocrisy theme is a general critique of pilgrims as was the critiquing of the pilgrimage, which was subsumed under the theme of authenticity. The pain and suffering that pilgrims seek to endure during the Camino was integrated into the pilgrimage as a tourist product. Alcohol consumption and technology were subsumed under the social pressure category. From Table 2 , three main categories of themes emerged: (1) authenticity, (2) social pressure, and (3) pilgrimage as a tourist product.

\section{Results}

Due to the hectic nature of modernity, there is a desire to engage with nature and reflect upon a time before industrialization (Egan, 2010). Pilgrims seek to escape the ways of modern living through spiritual travel (Xiarhos, 2016). However, the modern pilgrim often continues to be fixated on technology and remaining connected to social media, e-mail, and the news (Antunes and Amaro, 2016). As a result, in many ways, it seems difficult to remain an authentic pilgrim in a modernized world as technology has changed the pilgrim experience (Digance, 2006). Contrary to tradition, modern pilgrims are typically middle- or upper-middle class, from urban centers of affluent societies that possess heightened-levels of education (Mendel, 2010). To this end, the modern pilgrim is able to afford the luxury of taking a month off of their responsibilities to travel to Europe (Mendel, 2010).

\section{Authenticity}

Following tradition, after walking approximately $40 \mathrm{KMs}$ from Saint-Jean-Pied-de-Port to Espinal carrying a 17 kilogram bag, I stayed in a refuge on my first night. The experience was as described by Slavin (2003) - sleeping was impossible. I felt that continuing the unpleasantness was not conducive to an enjoyable experience. After the first night, I refused to leave my sleeping accommodations up to fate. I decided to book my accommodations in advance. I also no longer stayed in refuges, but rather hotels with private accommodations. After the first day on the Camino, I began to act contrary to the pilgrim authentic behaviors.

After my third day, walking from Pamplona to Villatuerte, another $40 \mathrm{KMs}$, I met a pilgrim from the United States whom I was complaining to about walking with such a heavy bag. I was informed about a shipping service targeted specifically toward pilgrims. This logistics service provider picks up one's bag from their hotel and ships it to the next location for a marginal fee of $€ 4$. On my fourth day, I began using this service and continued until the end of my journey. Although I felt that this was not a perceived authentic approach to the pilgrimage, I knew that I would have a more enjoyable experience.

I found the next day, without the bag, to be a far more enjoyable journey. The decision to book accommodations in advance further removed the stress of worrying about finding a place to sleep. I actually started enjoying my time on the Camino. After that experience, I decided to simply be myself, behave as I normally would, and not adjust myself to suit the interests of those on the Camino. To this end, I was staying in rooms, comparable to my lifestyle, eating food that I normally would eat, and not carrying a large, heavy bag, which I have never done before in my life. If these behaviors would be considered unauthentic or unconventional, that would be fine with me. Consistent with my observations of the pilgrimage, Xiarhos (2016) argues that just because one completes the pilgrimage differently than the masses, it does not mean that the experience is any less valid or transformative.

Although the traditional pilgrim does not judge others or perceives him or herself as 'higher' than others (Plichta, 2016), due to many pilgrims holding, at times somewhat dogmatically, onto the importance of authenticity, many pilgrims often consider their 
pilgrimage as more authentic than those of other people (Jeffrey, 2018). As a result of my perceived inauthenticity, other pilgrims began treating me differently. Some of them were not particularly welcoming to me when I would pass them in the road. When I would say hello or wish them a pleasant journey, which is customary, some would ask me where my bag was. Several times a day, people would laugh at me and ridicule my small bag as I passed them on the road. Without my approval, people would take pictures of me to show others how small my bag was. To them, I was unauthentic. Although they were not hostile, they were not particularly pleasant as I was made to feel lessworthy. In many ways, I felt excluded from their interactions. This felt quite alienating. For the first time in my life, I knew what it felt like to be bullied.

\section{Critiquing pilgrimage}

Although I had positive experiences on the Camino, as a result of the negative ones, within the context of authenticity, I began to critique, heavily, the pilgrimage and pilgrims, in general. Throughout the pilgrimage, I could not help, but compare the Camino to the Hollywood film, The Wizard of Oz. In the film, four friends meet on a pilgrimage. They walk together, by following a yellow-bricked road, to Oz, a mystical location. The purpose of visiting $\mathrm{Oz}$ is to meet the Wizard of $\mathrm{Oz}$ whom, they believe, will solve their alleged problems. Similarly, in the case of the Camino, individuals walk, meeting people along the road to Santiago, with the hopes that their problems in life will be resolved through self-reflection by the time that they arrive to Santiago. Although not a golden-bricked path, the road to Santiago is marked by yellow markers.

I shared some of my critical views about the Camino with other pilgrims, whom I perceived, like me, where unauthentic. Over dinner with two North American pilgrims - one authentic and the other, like me, unauthentic - I began critiquing the pilgrimage. In particular, I expressed my dismay associated with the rules. Although the rules are simple, as outlined above, certain pilgrims feel that they need to add to them and act condescendingly toward those whom do not appear to be as 'pure' as they are. Lopez (2013) demonstrated that a pilgrimage is supposed to be an anti-structural experience that operates contrary to the established order of contemporary society. Ironically, even in this anti-structural approach to living, I found the Camino to be heavilystructured and confining.

\section{Critiquing pilgrims}

Throughout my interactions with authentic pilgrims and pilgrims, in general, I noticed various instances of hypocritical behavior ${ }^{1}$. Acting condescendingly toward other pilgrims, because they decided to travel the Camino to suit their needs, tastes, and preferences, seems contradictory to the welcoming nature that the Camino is all about. The following anecdote exemplifies this contradiction:

I had a nice dinner yesterday. It was just an Italian man and I. He was telling me about his experiences along the Camino. He said how it's about enjoying every little bit. Enjoying life. That everything is a blessing. That everything is beautiful and that we have to smell the roses because life is so fast and stressed. The Italian man just walks and doesn't make reservations. He said that is not what the Camino is about. The Camino is about the Catholic Church. The Camino is about welcoming others and being supportive... I saw my Italian friend from a few nights back today on the trail. I stopped to chat with him, but he ignored me today. Maybe it was because he saw my pink bag. I guess that I'm not pure enough for him, which is inconsistent with our previous conversation about the Camino as it is supposed to be about being open to others.

May $20^{\text {th }}, 2016^{2}$

Not only were people on the Camino less welcoming, they suggested that unauthentic pilgrims were taking it easy.

It was such a beautiful walk today that I was whistling. Along the way, there was an Austrian man who I walked with for a short while... he asked where my bag was and I told him that I

\footnotetext{
${ }^{1}$ I acknowledge, however, that hypocrisy is quite normal among people, in general, as they often behave in ways that are contradictory to their values or positions (Sykes \& Matza, 1957).

${ }^{2}$ Throughout the results section, the excerpts provided are taken, directly, from my personal travel journal.
} 
The Wrong Way: An alternative critique of the Camino de Santiago.

have been shipping it. He said that I was taking the easy way. How can you be taking the easy way when it's an $800 \mathrm{~km}$ walk?

May $27^{\text {th }}, 2016$

These experiences caused me to reflect deeper and analyze the pilgrims further. This led me to consider their lives, outside of the Camino, which as Slavin (2003) suggested, many people on the Camino do not talk about. Similarly, I noticed that those who travel the pilgrimage typically avoid talking about their personal lives. They tend to focus on the present. This might be associated with the fact that most pilgrims are from upper-middle class positions in society, but when they are travelling on the Camino, they are behaving in ways that are quite humble and very different from how they normally live. If individuals had discussed their formative lives, they might experience cognitive dissonance, defined as the mental discomfort that arises when individuals hold two or more competing and contradictory beliefs (Festinger, 1957). When individuals experience cognitive dissonance, tensions arises between one's self-concept as a good person and their ability to behave morally. To resolve this tension, individuals attempt to minimize this discomfort and, in the case of the Camino, they simply avoid talking about their lives (Slavin, 2003). This is consistent with how individuals typically reconcile the tension of cognitive dissonance avoidance (Berns et al., 2005).

... most people that can take a month off of work or school and travel to Europe on a holiday are well off upper-middle class, at the minimum. They have high salaries and big houses. They are not poor. So why would they come to Europe and live like a poor person for a month? They don't do it at home. Why here? Its hypocrisy... you're going to go home and say you lived a humble life for a month. What's the point? I think it's a slap in the face to all the people that are poor...

May 24 $4^{\text {th }}, 2016$

Conventional views suggest that part of the pilgrim experience involves attempting to behave similarly to a medieval pilgrim and, like others have noticed before me (e.g., Carbone et al., 2016), many pilgrims were pretending to act as though they were an ancient pilgrim. In extreme cases, a few pilgrims were traveling with donkeys (equipped with clanging pots hanging from them) and camping. One pilgrim, over dinner, suggested that because he was living modestly along the Camino, he now knows how those that are less-fortunate live.

Another pilgrim told us that on his first night in Roncevalles, the refuge ran out of beds. To accommodate the overflow, a gym, with concrete floors, was opened up. They slept on the concrete floors. Because it was freezing, some of the pilgrims went to a dumpster to get cardboard boxes to sleep on. Why would you do that? Why is it that the first port-of-call is to go to a dumpster to scavenge for something to sleep on as opposed to getting into a taxi and telling the driver to stop when they reach a hotel? ... He said that now he knows what it's like to be homeless. No you don't. You are just an upper-middle class, middle-aged man on vacation that is sleeping on a cardboard box acquired from a dumpster. You know nothing about being homeless. Why even say that? The hypocrisy is sickening. These people are on such a moral high horse with an aura of superiority because they slummed it.

May $18^{\text {th }}, 2016$

As suggested, the Camino has received significant exposure in popular culture and, as a result, I deduce that the recent influx of pilgrims is due to this publicity. However, when I spoke to other pilgrims about the reasons that they were walking the Camino, I was told that they were doing it for spiritual or religious purposes.

I saw some graffiti on a sign today that said 'This isn't Hollywood! Go home! This isn't The Way!' Let me tell you, these pilgrims on their high horses need to get down. So, these people are not pure enough for you? If they're here because of a movie, so what? Good for them. They saw a movie and liked it enough to want to go experience it. I think that's great... Most people on the pilgrimage are doing it because of popular culture. That's how we heard about it. Other than a few Europeans that are religious, everyone else is here because of a book, movie, or TV show and there is nothing wrong with that. 
Although I can sympathize that there are plenty of pilgrims in certain parts of the Camino, which makes it difficult to concentrate, these messages are unpleasant. As a result of these unwelcoming messages and, subsequent feelings of alienation, I could see how other pilgrims could have a difficult time.

\section{Social Pressures}

Consistent with the extant literature (e.g., Caidi et al., 2018), during my time along the Camino, I noticed various forms of social pressures that pilgrims encountered. Pilgrims experienced pressures from their responsibilities back home, pressures through social media, pressures surrounding the tension between consumerism and spirituality (Caidi et al., 2018), and pressures from other pilgrims on how one should behave. The tension and pressure from other pilgrims can be challenging for some to cope with, especially when comments are perceived as unpleasant. For example, Graham and Murray (1997, p. 402) provide an account of an American pilgrim who suggested that "... the Camino is not for people in cars, and he rails against the invasion of the Way by the 'latter-day Philistines - modern carpetbaggers' of UNESCO and the Council of Europe with their 'pretentious' signs." From my experiences and consistent with the extant literature (e.g., Graham \& Murray, 1997), the greatest pressure that I felt along the Camino was that from other pilgrims.

To avoid the perceived disdain from the authentic pilgrims, I noticed that the other unauthentic pilgrims would pretend that they were in fact authentic. To do this, they would conceal that they booked their accommodations in advance. Others would avoid talking about the alternative modes of travel that they were taking. Even when they were injured, pilgrims were very concerned about taking unconventional forms of travel, like buses or taxis. They did not want others to think that they were unauthentic, which seemed to cause unnecessary stress, anxiety, and further injury. To this end, I met a mother and daughter that were nursing an injury. I suggested that they should perhaps avoid carrying their heavy bags as this would put further pressure on their injury, but they were reluctant to ship their bag as they felt it was not the traditional approach to the pilgrimage.

I came across a mother and daughter today. They had spent three days in Burgos dealing with tendinitis and they seemed sore, tired, and not enjoying themselves. They seemed concerned about the self-flagellation. Because they were in so much pain, they took a bus at one point feeling very guilty after. I started telling them about why we should not be torturing ourselves. That it's masochistic, sick, and twisted. Enjoy yourself. Why put yourself through the misery if you don't have to? May $18^{\text {th }}, 2016$

Considering that the Camino has been and continues to be a way for pilgrims to take a break from the hectic aspects of their lives for personal reflection and growth, fundamentally, the pilgrimage is a form of escapism. Beyond the escapism that can be attained from the journey, itself, there were a myriad of escapism opportunities available along the Camino, namely: technology and, also, alcoholconsumption.

\section{Technology}

With the constant need to be connected to loved-ones, employment, friends, and the world of information technology, in general, I noticed the difficulties associated with escaping from modern living and removing all stressors on the Camino. Throughout the Camino, I found myself constantly thinking about the Internet and checking my e-mails. This experience taught me that I appear to have a mild addiction to the Internet. I do not believe that I am the only one with this dependence on the Internet. Throughout my time on the Camino, in the hotel lobbies or at restaurants, a majority of the pilgrims would be tethered to their technology. Updating their social media accounts, contacting loved-ones, taking pictures, and reviewing photographs taken that day. I even saw a middle-aged woman wearing a shirt that said: 'what is the WIFI password?' From my perspective along the Camino, many pilgrims took pictures wherever they went. It appears that they were living their experiences through the lens of a camera. In fact, when perceived authentic pilgrims arrived to the cathedral in Santiago de Compostela, they 
appeared to act awkwardly. They did not know what to do. To compensate for this, they often resorted to taking pictures of everything around them as opposed to absorbing their surroundings.

To this end, my perception is that our society, in general, has become mildly addicted to information technology devices as they help us escape from the monotony of our lives. Even when we are supposed to be escaping from this monotony, by walking on the Camino, for example, we have to escape from the pain, suffering, and unpleasantness associated with the Camino through technology. To this end, technology acts as an escapism from an escapism.

\section{Alcohol-consumption}

On the Camino, the pilgrim meals cost approximately $€ 10$ that include three-courses with wine. From my interactions with other pilgrims, they find that the alcohol, typically a bottle of wine, enables them to sleep better as the beds are uncomfortable and the rooms are noisy. Some have also suggested that it helps them to relax after a long day of trekking. It was considered a soother (and a great help) to the pain and suffering that they endure (and will continue to endure) along the Camino. In many ways, like in daily life where individuals rely on various forms of escapism, such as alcohol consumption, to escape the monotony and dissatisfaction associated with daily working life (Overall, 2017), they, too, on the Camino drown their sorrows in alcohol.

\section{Pilgrimage as a Tourist Product}

Consistent with the views of others (e.g., Higgins and Hamilton, 2011; Plichta, 2016), throughout my journey, I noticed the consumeristic nature of the Camino whereby travel service providers constantly compete for the business of pilgrims throughout the route to Santiago. Further to the route to Santiago, I noticed that many pilgrims appeared to be quite particular about the appropriate routes to follow. According to the most popular guidebook, namely Brierley (2013), it is suggested that pilgrims should follow the recommended routes. The recommended routes correspond to the markings, which are typically yellow arrows painted on buildings or roads, throughout the journey. Although many of these recommended routes are beautiful, the terrain is often unpleasant. The path can be slippery, muddy, and it has unnecessary inclines. During my second week on the Camino, when my knees started to cause me discomfort, mainly as a result of the terrain, I further embarked on unconventional behavior by no longer following the recommended routes in several places.

To this end, when I noticed that the recommended route went through a forest, I simply walked along the road, which in most cases, followed in parallel to the path. I found these non-recommended routes quite enjoyable as they were quiet, allowed me to reflect, and largely isolated from the hectic pilgrim convoys. On one foggy day, as I was walking through the hills of O'Cebreiro, I came upon another pilgrim who seemed lost:

She was looking for the arrows. I told her that she can take my way... she took it, but seemed nervous and concerned that it was not well-marked. I told her that you can find your way if you keep your sense of direction... These people get really nervous when they do something that's outside of the ordinary or unconventional. They want to conform to what is expected of you on this trek... It's funny to see them all look for the markers and get paranoid when they can't find them. I used to do that, but now I know the direction I'm walking pretty well - due west with the sun behind you - don't make any major turns and if you lose the Camino, it's not a big deal. May 29th, 2016

Often times, Brierley (2013) would suggest that the unconventional routes were either unsafe or unpleasant, aesthetically. From my experiences along the unconventional routes, I disagree.

The walk on the road was beautiful enough through the mountains. Who cares that it is under a six-lane highway? I think that a six-lane highway through the mountains is a feat of humankind ... the person that wrote the guidebook, like many pilgrims along the Camino, wants it to be like the 14th-century. Well, we can't go back in time.

May $30^{\text {th }}, 2016$ 
Whilst travelling through Najera, which is a busy transport hub, I noticed some very anxious pilgrims when checking into my hotel. There was a large line of pilgrims entering the hotel, many of them being turned away as a result of no vacancy. The problem is that if you leave your accommodations up to fate, pilgrims often have to continue walking to the next location, which can be anywhere from a couple of kilometers to 15 kilometers. If one is without accommodations, depending on the weather and the distance to the next town, it can be very distressing. To elaborate on this, when I walked into some towns around noon, I would see speed walking pilgrims. Others were running to get to the refuges so that they could line up and guarantee a bed for themselves. This was something that I was not prepared to do.

\section{Pain and suffering}

Consistent with the extant literature (e.g., Xiarhos, 2016), from my experiences along the Camino, I noticed that pain and suffering were intricate to the journey. Many pilgrims refused to send their bags to the next village as they believed that pilgrims must labor and suffer (Xiarhos, 2016). In particular, the Pilgrim's Way Friends Associations established a list of rules on how pilgrims should behave during their journey on the Camino:

Pilgrimage expresses the Christian idea of life as a stage leading to eternal and true life ... achieved through sacrifice, asceticism, and renunciation ... The passage of one's life through time is represented by the space through which one travels. Reaching the goal symbolically represents death but at the same time access to true life, rebirth achieved through the sacrifice made during the journey (Herrero, 2008, p. 134).

Many of the authentic pilgrims that I encountered were unpleasant and, sometimes, even miserable. I sympathize with their behavior because I acted the same way, perhaps worse, on my first day on the Camino. As mentioned, I carried my 17-kilogram pack for 40 kilometers and had a poor nights rest. I was so cynical, cranky, and critical that the next morning, other pilgrims excused themselves from my company. After two days of walking with my heavy bag for 87.1 kilometers, I began questioning my sanity.

However, unlike me and my unwillingness to endure unnecessary pain and suffering, many of the pilgrims that I spoke to perceived the pain and suffering as vitally important.

I walked past this woman today and she asked where my bag was. I told her that I sent it forward and she replied with "don't tell me that." I told her that the cost was dirt cheap and you can actually enjoy the walk. She told me that her bag was 10 kilograms and that she doesn't want to enjoy the walk. She wants to suffer. Why would you put yourself through this on vacation? An Austrian man, whom I saw at dinner last night, told me that it is not a vacation. That's exactly what it is, said I. If you don't have to work tomorrow, you're in another country, and it's not the weekend, you're on vacation. I then asked if she was staying at the refuges to which she replied that she was. I told her that I was staying in private accommodations to which she said for me to get away from her. She didn't want to hear anymore.

May $28^{\text {th }}, 2016$

I asked why she wanted me to leave her alone and from, her response, it seemed that she was questioning her decision and, perhaps, she thought that she made the wrong choice. This interaction showed me that other pilgrims were perhaps questioning themselves about why they were enduring the pain and suffering of the Camino.

I think that the reason that many people want to endure suffering is two-fold; first, they are led to believe that they are supposed to, as it is part of the experience. Second, it appears to be linked to Judeo-Christian religions whereby individuals, like Jesus, have to encounter pain in their lives. To this end, that is why religion and spirituality are so important to the Camino, in general.

When I was walking today, I had this thought about how our society is focused on negativity, death, or pessimism. To me, it is because of our foundation in Christian or Catholic value systems, which, like the Camino, is rooted in 
pain and suffering. It is a masochistic religion that is tainting us, to an extent, to focus on negativity, pain, suffering, and death, but mostly just looking at things in a negative, darker, grey sort of way ... our lives are focused on the endpoint our death via retirements and saving for the future.

June $2^{\text {nd }}, 2016$

Consistent with this interpretation, many of the religious imagery that $\mathrm{I}$ witnessed along the Camino further-emphasized the masochistic and sadistic nature of some religions:

I passed a church today. The monument above the door (see Figure 1) was a distraught Mary holding a dead Jesus. What a horribly unwelcoming image. It is horribly sadistic and twisted. An image of death on the door as you walk in. On the altar, inside the church, is another image of death - a man - Jesus - that has been nailed to a wooden plank.

May 28 $8^{\text {th }}, 2016$
Throughout the journey, I would walk into churches and reflect upon the imagery. I would consider the effect that this imagery, often with a focus on pain, suffering, and death pain is impacting people on the Camino and their desire to also endure suffering.

Christianity and Catholicism, in particular, are religions that are based on pain and misery. It is obvious and terrible even this pilgrimage - it is a penance, a masochistic undertaking. I don't understand the point in living that way. Why should we? Why is luxury frowned upon and wrong whilst the meek and humble are embraced? It goes back to religion whereby we are controlled and told to be happy with nothing.

May $28^{\text {th }}, 2016$

\section{Discussion}

The aim of this ethnographic study was to understand: (1) how the critiques of other pilgrims affect one's experiences and (2) how

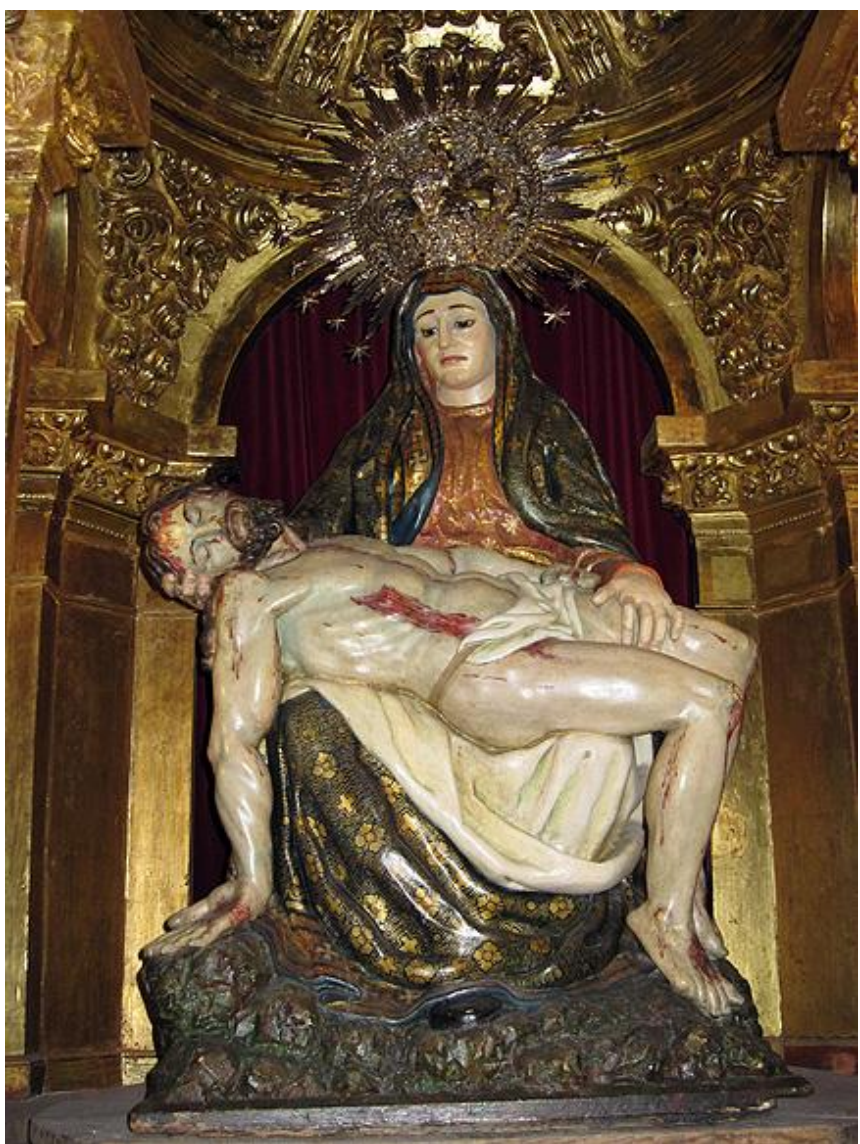

Fiaure 1. Monument on the Capilla de la Viraen de las Anaustias 
escapism affects the journey. In pursuit of understanding these aims, three important themes, namely: authenticity, social pressure, and pilgrimage as a tourist product, emerged from the ethnographic data.

Although an enjoyable experience, I found the criticism experienced along the Camino for those that do not follow the authentic approach to be challenging and alienating. Consistent with the observations of Graham and Murray (1997), I found that pilgrims were constantly feeling social pressure to behave authentically and were continuously worrying about how they were perceived by others. In this vein, they attempted to display authentic pilgrim behaviors. For a spiritual experience, people appear to be consumed with their ego and worried about what others think of them (Overall, 2017) ${ }^{3}$. Clearly, when the mind is consumed with these thoughts, the whole idea of the pilgrimage, namely self-reflection and inner growth, is difficult to achieve.

Within the context of authenticity, I noticed that many pilgrims had attempted to take the 'vow of poverty'. From my experiences and consistent with Kelner (2001), when pilgrims take the vow of poverty, they are behaving unauthentic to how they normally live. The authentic pilgrims who are largely middle- to upper-middle class, slept in uncomfortable settings, often with thirty people in the room, and lived humble, meek lives on the Camino. Mendel (2010) suggested that these contradictory behaviors amount to pilgrims taking advantage of the benevolence of the local population whom offer budget, or sometimes free, accommodations. By simulating themselves as authentic, these pilgrims were not only able to minimize their expenditures, but they were also able to enhance their status and social identity among others (Mendel, 2010). For those that succumbed to the social pressures to conform toward a more authentic pilgrim experience, a sense of belonging was provided. By doing

\footnotetext{
${ }^{3}$ Overall (2017) suggested that, through their purchasing patterns, individuals attempt to 'keep up with the Joneses' by consuming, similarly, as their friends, colleagues, and family members. They even attempt, through social media, for example, to demonstrate how luxurious their lives are, all with the desire to make others jealous.
}

this, perceived authentic pilgrims 'escape' from themselves along the journey, but return to their natural environment at the completion of their journey. Throughout this process, due to the disconnection between one's authenticity, dissonance occurs, which was observed among several pilgrims along my journey (e.g., the German pilgrim and the woman complaining about her pack). As a result of this perceived negativity associated with one's authenticity, the pilgrim experience, which is supposed to be a spiritual and uplifting journey, can be adversely affected.

Further, one can no longer live as a medieval pilgrim because the original context has been removed - it no longer exists and it does not apply- space, time, and context are not considered. One can only experience a pilgrimage that connects to the current context - anything that does not integrate this is unauthentic. When one attempts to live like a medieval pilgrim, he or she is merely attempting to resurrect the past. The past is behind us, the future is uncertain, all that we ever have is the present. In this way, Xiarhos (2016) suggests that a vital aspect of a pilgrimage is that the function and meaning change as individuals and societies evolve. Like culture, a pilgrimage cannot be static, but rather dynamic and constantly changing. Pilgrimages vary depending on tradition, the pilgrimage, and the pilgrim (Hill-Smith, 2009). As a result, there is no right way to participate in a pilgrimage (Kelner, 2001; Xiarhos, 2016). Belhassen et al., 2008 argued that the only way to engage in an authentic pilgrimage journey is to be authentic to oneself, which resonated with me throughout my experience. Conversely, in the case of those that were considered unauthentic pilgrims, their pride and selfesteem were negatively influenced, causing many to conceal their behavior.

To this end, as discovered through my time along the Camino and consistent with the extant literature (e.g., Higgins and Hamilton, 2011; Plichta, 2016), the Camino de Santiago has increasingly become an attractive tourist product for middle-aged and recently retired individuals. Hotels, transportation companies, travel service providers, restaurants, and bars in the towns, villages, and cities along the 
Camino de Santiago continuously compete for the pilgrim dollar. Although this competition leads to an improved experience for some, those that seek a more authentic experience, often have feelings of disdain toward the modern nature of the Camino (e.g., Graham \& Murray, 1997).

Throughout my experiences, I began to understand how escapism and the pain and suffering associated with the Camino might not be conducive to positive outcomes. To this end, the critical theorists of the Frankfurt School of Thought suggest that the monotony of daily life, often fueled by the system of production and consumption of modern living leads to feelings of alienation, defined as feelings of estrangement from oneself and others (Fromm, 1955; Marcuse, 1964). The system of production and consumption often leads people to live unsatisfying lives, which leads them to regret their life choices (Overall, 2017). Fromm (1955) suggests that this dissatisfaction contributes to feelings of unhappiness and depression, which he suggests is contributing to the mental pathology of society. To overcome these negative emotions, individuals rely on various forms of escapism, such as: consumption, technology, substance abuse, eating unhealthy foods, and entertainment (Horkheimer and Adorno, 1947; Marcuse, 2001). These avenues of escapism allow individuals to distract themselves, temporarily, from acknowledging the reality of their predicament.

As Egan (2010) suggested, many contemporary pilgrims embark on the Camino de Santiago as their lives have become stagnate, which has contributed to feelings of depression. Through the pilgrimage and, by extension, their absence from normal living, these pilgrims have been able to cast off, temporarily, various aspects of their identities. However, along the Camino, the pain and suffering continues. Pilgrims attempted to conceal the pain, suffering, and misery associated with the pilgrimage through alcohol consumption and information technology devices. The pain and suffering that one endures is aligned to religion where, like Jesus, individuals have to endure pain (through penance) to receive spiritual absolution and forgiveness. Those that possess an external locus of control, believe that if they endure the Camino, they will make God, karma, or the universe happy. It is believed that this will lead to their negative predicament somehow resolving itself leading to the rediscovery of a purpose in life. Although these spiritual epiphanies might make a pilgrim feel better, temporarily, the undertaking of experiencing pain and suffering might not be the most effective means to address the fundamental feelings of dissatisfaction or depression that sparked the initial need for the pilgrimage in the first place (Egan, 2010). At the end of the journey, most pilgrims have to resume their lives, which can be challenging for some, such as the German man who did not know how he would resume the monotony of his life. When life resumes, the issues that sparked their initial dissatisfaction remain intact. People rarely resolve the root of their unhappiness, namely their current living predicament. To endure it, many rely on further forms of escapism to conceal their unhappiness (Horkeimer \& Adorno, 1947).

\section{Practical implications}

There are several practical implications for pilgrims and tourists alike that seek to not only participate in the Camino de Santiago pilgrimage, but also for all pilgrimage experiences, in general. Individuals undertake a pilgrimage as a spiritual experience that hopefully leads to inward and personal development. Although many live an 'externally-focused' life whereby we become increasingly consumed by how others perceive us and how we measure up to others (Overall, 2017), the purpose of a pilgrimage is to look within. It is suggested that pilgrims should conduct their pilgrimage that is authentic to themselves and worry less about what others think about them. By changing one's focus from external to internal, pilgrims would be in an improved position to remove many of the social pressures that exist along the Camino de Santiago. This may ultimately improve the quality of the pilgrimage and enhance the experience. Finally, the pilgrimage is often taken as a form of escaping the monotony of daily life. These introspective journeys may reveal emotions that are difficult to process and integrate into one's life. However, by 
participating in pilgrimages, pilgrims may be in an improved position to understand the areas of their lives that trigger the need to 'escape', which may ultimately aid them in working toward addressing these through their integration upon return. This may include continuing their spiritual journey when they return home by participating in spiritual activities, such as: meditation, yoga, spiritual counseling sessions, which may help these post-pilgrims lead a more fulfilling life.

\section{Limitations and Future directions}

By uncovering the challenges of the modern pilgrim within the context of authenticity, the main contribution to knowledge of this research involves detecting how escapism - from oneself (by behaving in a perceived inauthentic way to how one typically behaves) and one's context - may not address the root of one's dissatisfaction. Although valuable, this research is not without its limitations. First, the data used for this qualitative research was based on personal observations. As a result, the typical limitations, namely a lack of generalizability, apply. To overcome this, researchers may wish to consider a mixed method approach that can combine the data richness of qualitative methodologies with the generalizability of quantitative methods. Second, this research was based on the Camino de Santiago with predominantly middle- and upper-middle class North American and Western European participants, which further limits generalizability of the findings. To reconcile this, researchers may wish to investigate how the studied phenomena affect those from other cultural contexts and class systems travelling through non-Western contexts.

\section{References}

Antunes, A. and Amaro, S. (2016) Pilgrims' acceptance of a mobile app for the Camino de Santiago. In A. Inversini, R. Schegg (Eds.), Information and Communication Technologies in Tourism. Springer International Publishing Switzerland, pp. 509-522.

Belhassen, Y., Caton, K., and Stewart, W.P. (2008) The search for authenticity in the pilgrim experience. Annals of Tourism Research, 35(3), 668-689.

Berns, G.S. Chappelow, J. Zink, C.F. Pagnoni, G. \& Martin-Skurski, M.E. (2005) Neurological correlates of social conformity and independence during mental rotation. Biological Psychiatry, 58,245-253.

Brierley, J. (2013) A Pilgrim's Guide to the Camino de Santiago. The Way of St. James. The ancient pilgrim path also known as Camino Frances. Camino Guides. Forres, Scotland.

Bryman, A. and Teevan, J.J. (2005) Social research methods, Canadian Edition. Oxford University Press, ON, Canada.

Caidi, N., Beazley, S., Marquez, L.C. (2018) Holy Selfies: Performing Pilgrimage in the Age of Social Media. The International Journal of Information, Diversity, \& Inclusion, 2(1-2), 933.

Carbone, F., Corinto G. and Malek, A. (2016) New Trends of Pilgrimage: Religion and Tourism, Authenticity and Innovation, Development and Intercultural Dialogue: Notes from the Diary of a Pilgrim of Santiago. AIMS Geosciences, 2(2), 152-165

Cohen, E. (1988) Authenticity and commoditization in tourism. Annals of Tourism Research, 15, 371-386.

Collins-Kreiner, N. and Wall, G. (2015) Tourism and religion: Spiritual journeys and their consequences. In S.D. Brunn (ed.), The Changing World Religion Map. Springer Science Business Media Dordrecht, pp. 689708.

D'Andrade, R. (1995) The development of cognitive anthropology. Cambridge: Cambridge University Press.

Digance, J. (2006) Religious and secular pilgrimage: Journeys redolent with meaning. In D.J. Timothy and D.H. Olsen. Tourism, Religion \& Spiritual Journeys. Routledge Contemporary Geographies of Leisue, Tourism and Mobility, pp. 36-48.

Dominguez, M.D.M.R. and Alonso, M.V. (2019) Religious tourism in Galicia: The case of El Camino de Santiago. In J. Alvarez-Garcia, M. de la Cruz del Rio-Rama, M. GomezUllate, Handbook of Research on SocioEconomic Impacts of Religious Tourism and Pilgrimage.

Egan, K. (2003) Walking back to happiness? Modern pilgrimage and the expression of suffering on Spain's Camino de Santiago. Journeys, 11(1), 107-132.

Festinger, L. (1957). A Theory of Cognitive Dissonance. Stanford, CA: Stanford University Press.

Fromm, E. (1955) The Sane Society. New York: Henry Holt and Company, LLC. 
Graham, B. and Murray, M. (1997) The spiritual and the profane: The pilgrimage to Santiago de Compostela. Ecumene, 4(4), 389-410.

Herrero, N. (2008) Reaching 'Land's End': new social practices in the pilgrimage to Santiago de Compostela. International Journal of Iberian Studies, 21(2), 131-151.

Higgins, L. and Hamilton, K. (2011) Sacred Places: an Exploratory Investigation of Consuming Pilgrimage, NA - Advances in Consumer Research, Volume 38, (Eds). Darren W. Dahl, Gita V. Johar, and Stijn M.J. van Osselaer, Duluth, MN: Association for Consumer Research.

Hill-Smith, C. (2009) Cyberpilgrimage: A Study of Authenticity, Presence and Meaning in Online Pilgrimage Experiences. Journal of Religion and Popular Culture, 21(2), 1-17.

Horkheimer, M., and Adorno, T.W. (1947) Dialectic of Enlightenment. Stanford: Stanford University Press.

Jeffrey, J. (2018) The making of a modern pilgrim. The Humanist, January/February 2018, 2531.

Kelner, S. (2001). Narrative construction of authenticity in pilgrimage touring. Paper Presented at the 96th Annual Meeting of the American Sociological Association Anaheim, California, 1-21.

Lopez, L. (2013) How long does the pilgrimage tourism experience to Santiago de Compostela last? International Journal of Religious Tourism and Pilgrimage, 1(2), pp. 1-14.

Marcuse, H. (1964) One-dimensional Man. Boston: Beacon.

Mendel, T. (2010) Foot-pilgrims and backpackers: contemporary ways of travelling. Scripta Instituti Donneriani Aboensis, [S.I.], v. 22, p. 288-315, jan. 2014. ISSN 2343-4937. Available at: <https://ojs.abo.fi/ojs/index.php /scripta/article/view/360>. Date accessed: 13 Feb. 2017.

Murray, M. (2014) The cultural heritage of pilgrim itineraries: The Camino de Santiago. Institute of Spatial and Environmental Planning. Queen's University Belfast. Working Paper No. 6, 1 - 60.

Nilsson, M. (2013) Post-Secular Tourism: A Study of Pilgrimages to Santiago de Compostela. Karlstad University, Faculty of Arts and Social Sciences (starting 2013), Department of Geography, Media and Communication (from 2013). ORCID iD: 0000-0002-57905922. http://kau.diva-portal.org/smash/rec ord.jsf?pid=diva2\%3A886256\&dswid=1049

Ojastu, D., Chiu, R. and Olsen, P.I. (2011). Cognitive model of entrepreneurship and its reflection in education, Journal of Enterprising Culture, 19(4), 397-434.

Overall, J.S. (2017) All around the mulberry bush: A theory of cyclical unethical behaviour. International Journal of Business and Globalisation. Accepted for publication and in press.

Overall, J.S. Wise, S. (2016) The antecedents of entrepreneurial success: The importance of travel. Journal of Enterprising Culture, 24(3), 1-33.

Oviedo, L. de Courcier, S. Farias, M. (2013) Rise of pilgrims on the Camino to Santiago: Sign of change or religious revival? Review of Religious Research, 56(3), 433-442.

Plichta, P. (2016) "We were like pilgrims from the $12^{\text {th }}$ century. This is something! I do not praise, I appreciate it." Camino de Santiago in the memories of Polish peregrinos. Czlowiek I Spoleczenstwo, XLI, pp. 189-209.

Robson, C. (2002) Real world research, 2nd edition. Blackwell Publishing, MA.

Santos, X.M. (2002) Pilgrimage and Tourism at Santiago de Compostela. Tourism Recreation Research, 27(2), 41-50.

Silverman, D. (2008) Interpreting qualitative data, 3rd edition. Sage Publications, UK.

Slavin, S. (2003) Walking as spiritual practice: The pilgrimage to Santiago de Compostela. Body \& Society, 9(3), 1-18.

Smith, A.T. (2018) Walking meditation: Being present and being pilgrim on the Camino de Santiago. Religions, 9(3), 82.

Strauss, A. and Corbin, J. (1990). Basics of Grounded Theory Methods. Beverly Hills, CA: Sage.

Suddaby, R. (2006), From the editors: What grounded theory is not, Academy of Management Journal, 49(4), 633-642.

Sykes, G.M., \& Matza, D. 1957. Techniques of neutralization: A theory of delinquency. American Sociological Review, 22(6), 664-670.

Warkentin, B. (2018) Spiritual but not religious: The fine line between the sacred and secular on the Camino de Santiago. Social Work and Christianity, 45(1), 109-121.

Xiarhos, M. (2016) Authenticity and the Cyber Pilgrim. Journal of Religion \& Society, 18, 111. 